\title{
Placement of an antibiotic oral pack on the hard palate after primary cleft palatoplasty: a randomized controlled trial into the effect on fistula rates
}

\author{
Rajgopal R. Reddy ${ }^{1,2,3} \cdot$ Srinivas Gosla Reddy ${ }^{1} \cdot$ Bhavya Banala $^{4} \cdot$ Ewald M. Bronkhorst ${ }^{5} \cdot$ Ann W. Kummer ${ }^{6}$. \\ Anne Marie Kuijpers-Jagtman ${ }^{7} \cdot$ Stefaan J. Bergé $^{8}$
}

Received: 18 October 2016 / Accepted: 21 November 2017 / Published online: 30 November 2017

(C) The Author(s) 2017. This article is an open access publication

\begin{abstract}
Objective The objective of this study is to determine whether placement of an antibiotic oral pack on the hard palate reduces fistula rates after primary cleft palatoplasty.

Subjects and methods This study was a parallel blocked randomized controlled trial. The study consisted of two groups of 100 patients each with non-syndromic unilateral complete cleft lip, alveolus, and hard and soft palate that underwent primary palatoplasty. Group A had an oral pack placed on the hard palate for 5 days postoperatively while group B did not. Occurrence of fistulae between both groups was tested using odds ratios (OR).

Results In $2 \%$ of the patients in group A, a fistula was found 6 months after palatal surgery. In contrast, in $21 \%$ of the patients in group $\mathrm{B}$, a palatal fistula could be confirmed. The fistula occurrence in group A was statistically significantly lower than that in group $\mathrm{B}(\mathrm{OR}=0.0768, \mathrm{CI}=[0.02 \ldots 0.34], p<0.001)$.

Conclusion The findings of this study provide evidence that the rate of fistula formation after primary palatoplasty is significantly reduced if a pack soaked with antibiotic cream is placed on the palate postoperatively for 5 days.

Clinical relevance The use of an antibiotic pack after cleft palate repair can be recommended to prevent occurrence of oronasal fistulae.
\end{abstract}

Keywords Cleft palate $\cdot$ Surgical procedures, operative $\cdot$ Oral fistula $\cdot$ Treatment outcome

\section{Introduction}

Primary closure of a cleft palate should result in an intact palate with separation of the oral and nasal cavity [1]. Breakdown of the primary cleft palate repair causes oronasal

Rajgopal R. Reddy

raj@craniofacialinstitute.org

1 Cranio-maxillofacial Surgery, G.S.R. Hospital, Institute of Cranio-Maxillofacial and Facial Plastic Surgery, Vinay Nagar Colony, Saidabad, Hyderabad, India

2 Department of Dentistry, Radboud University Medical Center, Nijmegen, The Netherlands

3 GSR Institute of Craniofacial Surgery, \# 17-1-383/55, Vinay Nagar Colony, IS Sadan, Saidabad, Hyderabad 500059, India fistulas with consequent dysfunction. Such fistulas are reported to occur between 0 and $77.8 \%$ of patients after primary palatoplasty [2]. Though the breakdown of a primary repaired cleft palate could be due to a number of reasons, localized infection may be a significant cause.
$4 \quad$ Speech and Language Therapy, G.S.R. Hospital, Institute of Cranio-Maxillofacial and Facial Plastic Surgery, Vinay Nagar Colony, Saidabad, Hyderabad, India

5 Department of Cariology and Preventive Dentistry, Radboud University Medical Center, Nijmegen, The Netherlands

6 Division of Speech-Language Pathology, Cincinnati Children's Hospital Medical Center, University of Cincinnati College of Medicine, Cincinnati, OH, USA

7 Department of Orthodontics and Craniofacial Biology, Radboud University Medical Center, Nijmegen, The Netherlands

8 Department of Cranio-maxillofacial Surgery, Radboud University Medical Center, Nijmegen, The Netherlands 
Infection of any open post-surgical site is a known phenomenon, especially if the site is open to food particles. Furthermore, mechanical trauma to the hard palate after palatoplasty could be caused by the patient putting his/her fingers in the mouth, eating food that is not soft, or being bottle-fed with the feeding bottle nipple resting on the hard palate. Placing an oral pack made out of a folded piece of sterile gauze soaked in antibiotic cream on the hard palate for 5 days postoperatively could address any injury to the healing tissue caused by localized infection or mechanical trauma. The aim of this study was to investigate whether placement of an antibiotic oral pack on the hard palate reduces fistula rates after primary cleft palatoplasty.

\section{Materials and methods}

\section{Trial design}

This study was conducted to ascertain whether the placement of a postoperative oral pack reduces fistula rates after primary repair of the cleft palate. The study design was a parallel blocked randomized controlled trial. As this is a surgical trial, the surgeon and patients could not be blinded for the treatment.

This study was conducted from June 1, 2012 to August 31, 2013, at the GSR Institute of Craniofacial Surgery, Hyderabad, India, which is a high-volume cleft center where 1400 cleft surgeries are performed every year. The local Ethical Committee approved the research protocol (ETH/ GSRICFS/2011/DEC 2) based on the guidelines declared by the Government of India. All participants and parents, if the participants were minors, were informed about the study and signed a written informed consent. Reporting of the trial in this paper follows the CONSORT (Consolidated Standards of Reporting Trials) statement [3].

\section{Eligibility and randomization}

Inclusion criteria for this study were non-syndromic complete unilateral cleft lip and palate with a previously repaired cleft lip; palate repair was planned at the age of 12 months. Exclusion criteria were bilateral cleft lip and palate, isolated cleft palate, patients older than 13 months of age, and patients with associated syndromic conditions.

To detect a reduction of fistula rates with a placement of a palatal pack after primary palatoplasty, which we estimated to reduce by $15 \%$ with a two-sided $5 \%$ significance level and a power of $80 \%$, a sample size of 200 was necessary. The intake period was anticipated to be 15 months to recruit the required number of patients.

Patients who fulfilled the eligibility criteria were randomly assigned to either group A or B. The randomization sequence was generated by a computer program (Sealedenvelope ${ }^{\mathrm{TM}}$,
Sealed Envelope Ltd., London, UK) using blocked randomization in block sizes of 20 in each block. Within each block, participants were randomly assigned numbers by a computerized program to one of the two treatment groups. The randomization was performed by one speech therapist (BB). The surgeon was blinded to the randomization process. After assigning the treatment method, the patients' parents were informed of the treatment plan by the speech therapist (BB). If the parents did not agree to the treatment plan assigned randomly to their child, the patient was excluded from the study and the number was assigned to the next patient on the list.

\section{Interventions}

One surgeon (RRR) performed palatal surgery on all patients in groups A and B. The Bardach two-flap technique with optimal muscle dissection was the surgery of choice in both groups. The patients in group A $(n=100)$ received an oral pack made of sterile cotton gauze soaked in framycetin sulfate antibiotic cream (Soframycin Skin Cream, Sanofi India Limited, India) for 5 days postoperatively (Fig. 1). This pack was sutured in such a way that it was closely adhering to the hard palate. The patients of group B $(n=100)$ had no pack placed postoperatively. In patients where the pack was placed, it was removed after 5 days. All patients in groups A and B were given intravenous and oral antibiotics, conforming to the hospitals' pediatric surgical protocol, i.e., two doses of intravenous injection cefotaxime $25 \mathrm{mg} / \mathrm{kg}$ body weight 12th hourly for the first $24 \mathrm{~h}$ postoperatively. This is followed by oral suspension amoxicillin and clavulanic acid $25 \mathrm{mg} / \mathrm{kg}$ body weight 12th hourly and syrup metronidazole $20 \mathrm{mg} / \mathrm{kg}$ body weight 8 th hourly. These medications are given for 5 days.

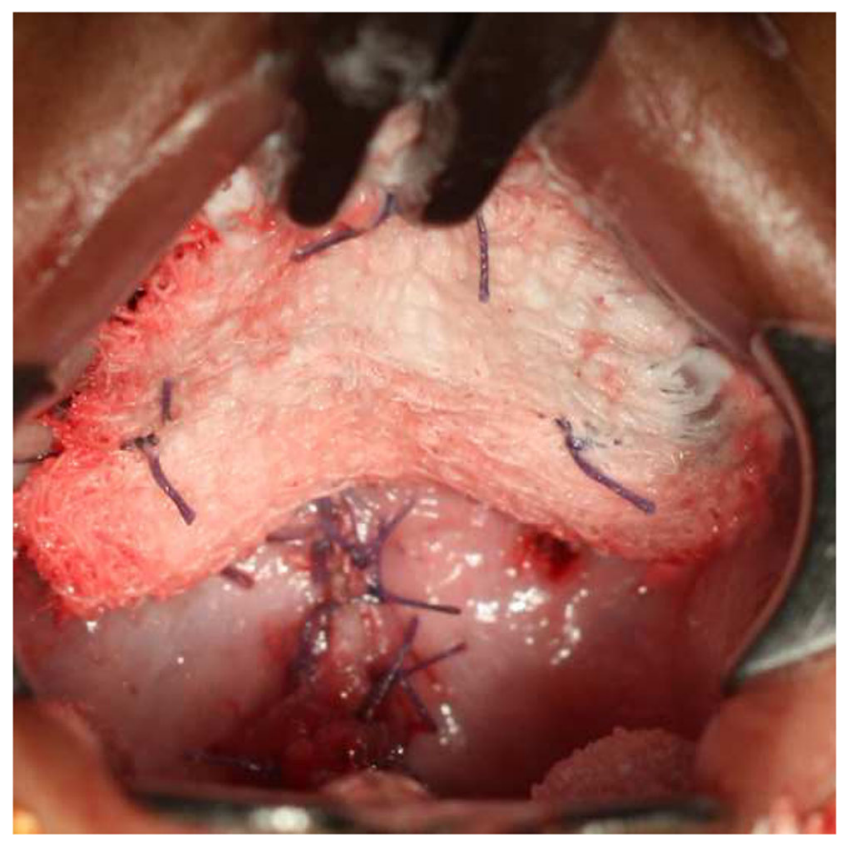

Fig. 1 Palatal pack placed on the hard palate 
Postoperative feeding was done orally for all patients included in this study.

\section{Outcome}

Patients in groups A and B were recalled after 6 months to clinically examine them for presence of fistulae. A single examiner (RRR) performed the examination to elicit the presence or absence of fistula. The examiner was blinded to whether the patient had a pack placed postoperatively or not. Fistula occurrence was tested visually as the first stage. If there was no visual sign of a fistula, history of nasal regurgitation was elicited. If the patient and/or parent gave a history of nasal regurgitation, a blunt periodontal probe was used to confirm a fistula in the hard palate.

\section{Statistical methods}

The statistical analysis was performed with SPSS version 22 (Chicago, IL, USA). Occurrence of fistulae in the study was tested using odds ratios.

\section{Results}

The flow of participants through each stage of the study is detailed in Fig. 2. All patients in groups A and B were operated between 12 and 13 months of age.

Of the patients in group A (with the oral pack), only $2 \%$ showed a fistula 6 months after palatal surgery. In contrast, in $21 \%$ of the patients in group B (without the oral pack), a palatal fistula could be confirmed. All the fistulae that were observed were present in the hard palate region. There were no fistulae present at the junction of the hard and soft palate. There was no instance of wound dehiscence in the soft palate region.

The fistula occurrence in group A was statistically significantly lower than that in group $\mathrm{B}(\mathrm{OR}=0.0768, \mathrm{CI}=[0.02 \ldots$ 0.34 ], $p<0.001$ ) (Table 1).

\section{Discussion}

Effective palatal fistula management has to be practiced by cleft teams to ensure that occurrence is minimized. Nevertheless, the incidence of fistula occurrence after primary palatoplasty in patients with palatal clefts has been reported to range between 0 and $77.8 \%$ [2]. Based on a systematic review on incidence of palatal fistulae after primary palatoplasty performed by Hardwicke et al. in 2014, fistula rates in 44 studies included in the review ranged between 0 and $35 \%$ [4]. Five studies included in the systematic review showed no postoperative fistula [2, 5-8], while two studies reported a high fistula rate of 34 and $35 \%$, respectively $[9,10]$.
Several studies have searched for an association between the severity of the palatal cleft and the rate of fistula formation [1, 11-13]. Some authors have attempted to isolate factors that would cause fistulae. The most common ones include tension of palatal soft tissue after palatal repair, upper respiratory infection, postoperative hemorrhage, failure of a multilayer closure, and cleft severity $[1,11]$. However, none of the studies conclusively proved that the severity of the cleft has a clear association with fistula occurrence. There are no studies that have attempted to correlate the formation of fistulae with factors such as localized infection or mechanical trauma. The present study was performed to test a possible reduction of fistula rates by placing a temporary barrier between the hard palate and the oral environment to reduce mechanical trauma and by the use of an antibiotic cream to reduce infections. The antibiotic pack was kept in place for 5 days at which stage the proliferative phase leads to the maturation phase of healing by primary intention [14].

Various studies have used palatal splints, bandages, and other devices in order to reduce the occurrence of palatal fistulae. The most common appendage used is acellular dermal grafting [15-20]. Another possibility to protect the hard palate after closure is an acrylic splint or a celluloid acetone dressing [21, 22]. We preferred the antibiotic cream-soaked sterile gauze pack to other barriers like acellular dermal matrices or acrylic splints for a number of reasons. An antibiotic-soaked sterile gauze pack is readily available at the time of surgery and it is cost-effective; it does not need to be manipulated into a shape and once placed, it takes the natural shape of the palate due to the pressure exerted by the tongue. Acellular dermal matrix and iodoform gauze was not used due to their higher costs and difficulty to procure in India. Acrylic splints were not used due to the time taken for preparing a splint and the possibility of an adverse reaction of the palatal mucosa to acrylic.

This study was a parallel blocked randomized controlled trial. The patients were divided into two groups that received an antibiotic-soaked gauze pack (group A) and did not have any pack placed postoperatively (group B). In this study design, we cannot exclude that the antibiotic cream in the pack had a positive influence. As we found in the present study that the rate of fistula formation after primary palatoplasty is significantly reduced if a pack soaked with antibiotic cream is placed on the palate as compared to no pack, we could perform another study in the future comparing an oral pack with and without antibiotic cream. Before performing such a study, we need to know if food debris adherence to the pack could be a focus of infection for an open post-surgical wound in the oral cavity. Though we did not find any literature to correlate such a presumption, we assumed that a pack made of gauze without antibiotic cream could be detrimental to the patient. This study also excluded patients that did not agree with the treatment plan randomly assigned to them. This was done in contravention of the intention to treat principle of randomized controlled trials. However, though the patients were 
Fig. 2 Flow diagram detailing the workflow through the trial

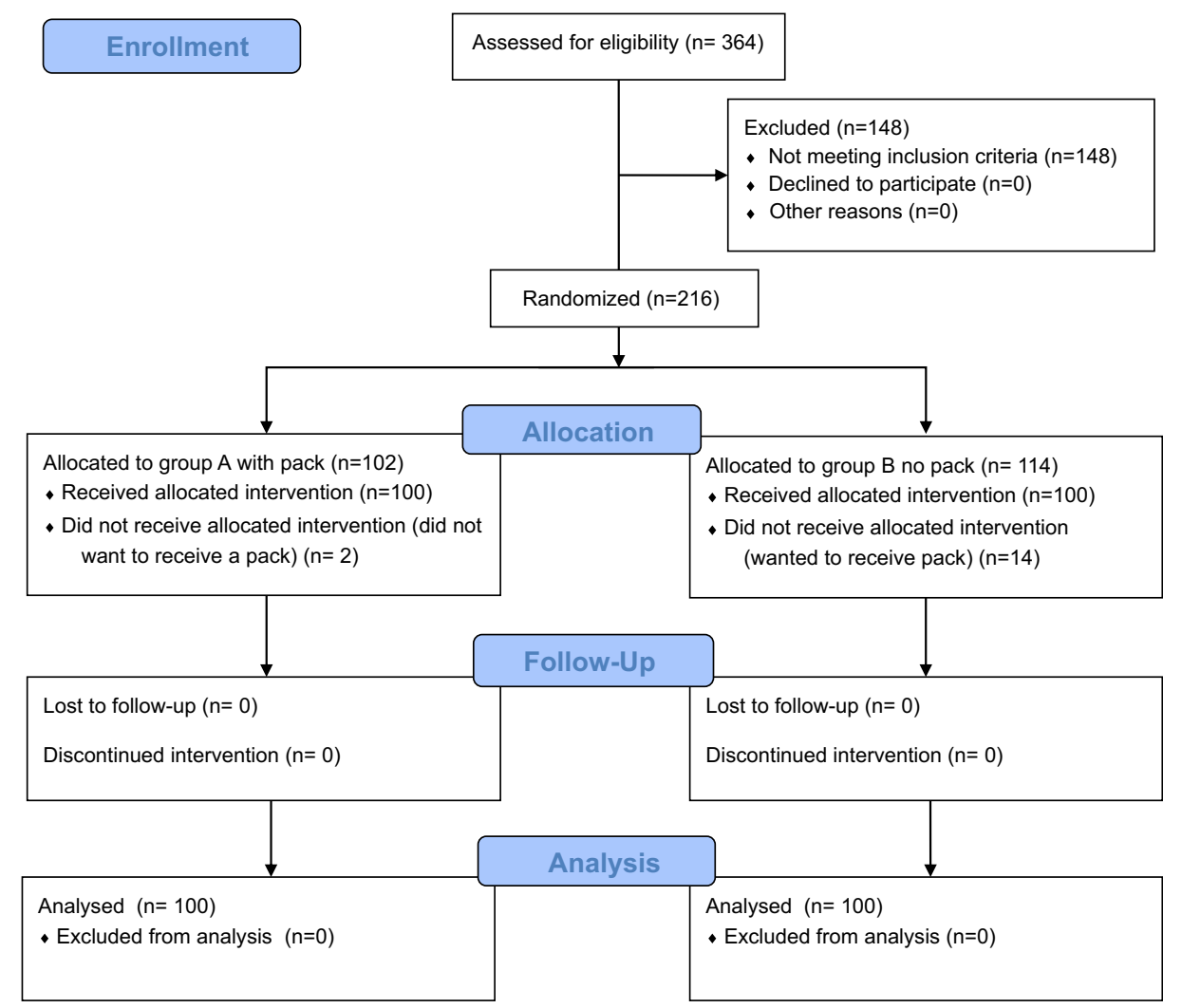

excluded from the study, the treatment plan of the patients was completed as requested by them.

Different surgical techniques have been used for primary repair of the cleft in the hard palates like the Bardach two-flap, von Langenbeck, and single-layer mucoperiosteal flaps [23, 24]. Similarly, different techniques like local mucoperiosteal flaps, turnover flaps from the palate, tongue flaps, pharyngeal flaps, buccal myomucosal flaps, facial artery musculo-mucosal flaps, free grafts of bone, cartilage, or dermal fat, free tissue transfer for large or recalcitrant fistulae, and acellular dermal matrix [25-37]

Table 1 Odds ratio of fistula presence after primary palatoplasty with (group A) and without (group B) oral pack

\begin{tabular}{llll}
\hline Primary palatoplasty & & \\
\hline & & $\begin{array}{l}\text { Group A } \\
(n=100) \\
\text { with pack }\end{array}$ & $\begin{array}{l}\text { Group B } \\
(n=100) \\
\text { no pack }\end{array}$ \\
\hline Fistula & Yes & 2 & 21 \\
& No & 98 & 79 \\
& Total & 100 & 100 \\
& Odds ratio & 0.0768 & \\
& $95 \%$ CI & {$[0.02 \ldots 0.34]$} & \\
& $p$ & $<0.001$ &
\end{tabular}

The fistula occurrence in group A was statistically significantly lower than that in group B as well as tissue engineering techniques [38] have been used to treat recurring fistulae. In the present study, local mucoperiosteal flaps were used in both groups (A and B) to repair the hard palate. To further standardize this study, all patients were treated using the Bardach two-flap technique. This ensured that a homogeneous group of patients treated by the same technique and by the same surgeon was studied for outcomes. The odds ratio of fistula formation after primary palatoplasty in children who did not have a pack placed increased statistically significantly. This means placing a pack postoperatively for patients undergoing primary palatoplasty was beneficial in context of oronasal fistulae in the hard palate. Which type of palatal pack is to be preferred in terms of fistula rate, patient comfort, and costeffectiveness needs to be investigated further.

\section{Conclusion}

The results of this study provide evidence that the rate of fistula formation after primary palatoplasty is significantly reduced if a pack soaked with antibiotic cream is placed on the palate postoperatively for 5 days.

Funding This study was partly funded by the World Health Organization Collaborating Centre for Oral Health Care Planning and Future Scenarios, Radboudumc, Nijmegen, The Netherlands.

Compliance with ethical standards 
Conflict of interest The authors declare that they have no conflict of interest.

Ethical approval All procedures performed in studies involving human participants were in accordance with the ethical standards of the institutional and/or national research committee and with the 1964 Helsinki declaration and its later amendments or comparable ethical standards.

Informed consent For this type of study, informed consent was obtained from all individual participants' parents included in the study.

Open Access This article is distributed under the terms of the Creative Commons Attribution 4.0 International License (http:// creativecommons.org/licenses/by/4.0/), which permits unrestricted use, distribution, and reproduction in any medium, provided you give appropriate credit to the original author(s) and the source, provide a link to the Creative Commons license, and indicate if changes were made.

\section{References}

1. Cohen SR, Kalinowski J, LaRossa D, Randall P (1991) Cleft palate fistulas: a multivariate statistical analysis of prevalence, etiology, and surgical management. Plast Reconstr Surg 87:1041-1047

2. Stewart TL, Fisher DM, Olson JL (2009) Modified von Langenbeck cleft palate repair using an anterior triangular flap: decreased incidence of anterior oronasal fistulas. Cleft Palate Craniofac J 46(3):299-304. https://doi.org/10.1597/07-185.1

3. Moher D, Hopewell S, Schulz KF, Montori V, Gøtzsche PC, Devereaux PJ, Elbourne D, Egger M, Altman DG (2010) CONSORT 2010 explanation and elaboration: updated guidelines for reporting parallel group randomised trials. BMJ $340(\operatorname{mar} 231)$ : c869. https://doi.org/10.1136/bmj.c869

4. Hardwicke JT, Landini G, Richard BM (2014) Fistula incidence after primary cleft palate repair: a systematic review of literature. Plast Reconstr Surg 134(4):618e-6627

5. Xu JH, Chen H, Tan WQ, Lin W, Wu WH (2007) The square flap method for cleft palate repair. Cleft Palate Craniofac J 44:579-584

6. Tan WQ, Xu JH, Yao JM (2012) The single z-plasty for cleft palate repair: a preliminary report. Cleft Palate Craniofac J 49(5):635639. https://doi.org/10.1597/10-011

7. Nadjmi N, Van Erum R, De Bodt M, Bronkhorst EM (2013) Twostage palatoplasty using a modified Furlow procedure. Int J Oral Maxillofac Surg 42:551-558

8. Dong Y, Dong F, Zhang X, Hao F, Shi P, Ren G, Yong P, Guo Y (2012) An effect comparison between Furlow double opposing Zplasty and two-flap palatoplasty on velopharyngeal closure. Int J Oral MaxillofacSurg 41:604-611

9. Parwaz MA, Sharma RK, Parashar A, Nanda V, Biswas G, Makkar S (2009) Width of cleft palate and postoperative palatal fistula: do they correlate? J Plast Reconstr Aesthet Surg 62:1559-1563

10. Richard B, Russell J, McMahon S, Pigott R (2006) Results of randomized controlled trial of soft palate first versus hard palate first repair in unilateral complete cleft lip and palate. Cleft Palate Craniofac J 43(3):329-338. https://doi.org/10.1597/05-065R.1

11. Wilhelmi BJ, Appelt EA, Hill L, Blackwell SJ (2001) Palatal fistulas: rare with the two-flap palatoplasty repair. Plast Reconstr Surg 107:315-318

12. Emory RE Jr, Clay RP, Bite U, Jackson IT (1997) Fistula formation and repair after palatal closure: an institutional perspective. Plast Reconstr Surg 99:1535-1538

13. Schultz RC (1986) Management and timing of cleft palate fistula repair. Plast Reconstr Surg 78:739-747
14. Von den Hoff JW, Maltha JC, Kuijpers-Jagtman AM (2013) Palatal wound healing: the effects of scarring on growth. In: Berkowitz $\mathrm{S}$ (ed) Cleft lip and palate diagnosis and management, 3rd edn. Springer, London, pp 309-324. https://doi.org/10.1007/978-3642-30770-6 14

15. Helling ER, Dev VR, Garza J, Barone C, Nelluri P, Wang PT (2006) Low fistula rate in palatal clefts closed with the Furlow technique using decellularized dermis. Plast Reconstr Surg 117:2361-2365

16. Kirschner RE, Cabiling DS, Slemp AE, Siddiqi F, LaRossa DD, Losee JE (2006) Repair of oronasal fistulae with acellular dermal matrices. Plast Reconstr Surg 118:1431-1440

17. Losee JE, Smith DM, Afifi AM, Jiang S, Ford M, Vecchione L, Cooper GM, Naran S, Mooney MP, Serletti JM (2008) A successful algorithm for limiting postoperative fistulae following palatal procedures in the patient with orofacial clefting. Plast Reconstr Surg 122:544-554

18. Aziz SR, Rhee ST, Ziccardi VB (2011) Acellular dermal graft augmentation of primary palatoplasty: case report and review of the literature. J Am Assoc Oral Maxillofac Surg 69(4):1221-1224. https://doi.org/10.1016/j.joms.2010.05.002

19. Losee JE, Smith DM (2011) Acellular dermal matrix in palatoplasty. Aesthet Surg J 31(7 Suppl):108S-115S. https://doi. org/10.1177/1090820X11418216

20. Aldekhayel SA, Sinno H, Gilardino MS (2012) Acellular dermal matrix in cleft palate repair: an evidence-based review. Plast Reconstr Surg. 130(1):177-182. https://doi.org/10.1097/PRS. 0b013e318254b2dc

21. Honigmann K (1994) The celluloid-acetone-dressing in palatoplasty. Cleft Palate Craniofac J 31(3):228-229. https://doi. org/10.1597/1545-1569(1994)031<0228:TCADIP>2.3.CO;2

22. Bowers DG, Gruber H (1973) Use of acrylic obturators to protect suture lines in the hard palate. Plast Reconstr Surg 51(1):98-101. https://doi.org/10.1097/00006534-197301000-00028

23. Bardach J, Morris HL (1990) Multidisciplinary management of cleft lip and palate. Saunders, Philadelphia

24. Fisher DM, Sommerlad BC (2011) Cleft lip, cleft palate, and velopharyngeal insufficiency. Plast Reconstr Surg 128:342-360

25. Denny AD, Amm CA (2005) Surgical technique for the correction of postpalatoplasty fistulae of the hard palate. Plast Reconstr Surg 115(2): 383-387. https://doi.org/10.1097/01.PRS.0000148650.32055.01

26. Murrell GL, Requena R, Karakla DW (2001) Oronasal fistula repair with three layers. Plast Reconstr Surg 107:143-147

27. Honnebier MB, Johnson DS, Parsa AA, Dorian A, Parsa FD (2000) Closure of palatal fistula with a local mucoperiosteal flap lined with buccal mucosal graft. Cleft Palate Craniofac J 37(2):127-129. https:// doi.org/10.1597/1545-1569(2000)037<0127:COPFWA>2.3.CO;2

28. Van Damme PA, Freihofer HP (1996) Palatal mucoperiosteal expansion as an adjunct to palatal fistula repair: case report and review of the literature. Cleft Palate Craniofac J 33(3):255-257. https://doi. org/10.1597/1545-1569(1996)033<0255:PMEAAA >2.3.CO;2

29. Kummer AW, Neale HW (1989) Change in articulation and resonance after tongue flap closure of palatal fistula: case reports. Cleft Palate J 26(1):51-55

30. Argamaso RV (1990) The tongue flap: placement and fixation for closure of postpalatoplasty fistulae. Cleft Palate J 27(4):402-410. https:// doi.org/10.1597/1545-1569(1990)027<0402:TTFPAF>2.3.CO;2

31. Abdollahi S, Jabbari BMY, Reza R et al (2008) Results of difficult large palatal fistula repair by tongue flap. Rawal. Med J 33:56-58

32. Nakakita N, Maeda K, Ando S, Ojimi H, Utsugi R (1990) Use of a buccal musculomucosal flap to close palatal fistulae after cleft palate repair. Br J Plast Surg 43(4):452-456. https://doi.org/10.1016/ 0007-1226(90)90012-O

33. Rintala A (1990) Labiobuccal mucosal island flap for closure of anterior palatal fistulae. Br J Plast Surg 43:452-456 
34. Sarabahi S, Tiwari VK (2006) Orbicularis orismusculomucosal flap for anterior palatal fistula. Indian J Plast Surg 39(2):148-151. https://doi.org/10.4103/0970-0358.29543

35. Kuran I, Sadikoğlu B, Turan T, Hacikerim S, Baŝ L (2000) The sandwich technique for closure of a palatal fistula. Ann Plast Surg 45:434-437

36. Krimmel M, Hoffmann J, Reinert S (2005) Cleft palate fistula closure with a mucosal prelaminated lateral upper arm flap. Plast Reconstr Surg 116:1870-1872
37. Schwabegger AH, Hubli E, Rieger M, Gassner R, Schmidt A, Ninkovic M (2004) Role of free-tissue transfer in the treatment of recalcitrant palatal fistulae among patients with cleft palates. Plast Reconstr Surg 113:1131-1139

38. Liu J, Bian Z, Kuijpers-Jagtman AM, Von den Hoff JW (2010) Skin and oral mucosa equivalents: construction and performance. Orthod Craniofac Res 13:11-20 